\title{
A FORMAÇÃO DOCENTE PARA O TRABALHO COM ALUNOS SURDOS EM ESCOLAS REGULARES
}

\author{
LELIANE APARECIDA CASTRO ROCHA*
}

\begin{abstract}
RESUMO
A pesquisa voltou-se para os cursos de Formação de Professores e Pedagogia, em IES particulares, da cidade de São Paulo que, com base na Lei 10.436/2002 e no Decreto 5.626/2005, incluiu obrigatoriamente a disciplina de Língua Brasileira de Sinais - Libras. Metodologicamente, optamos pela investigação qualitativa, que privilegia o estudo do fenômeno com base nas percepções dos próprios sujeitos. A pesquisa traçou uma retrospectiva histórica da educação dos surdos e sua forma de interagir com outros surdos e com ouvintes, facilitando a comparação entre a proposta de integração e a proposta da inclusão no âmbito da escola. A coleta de dados formou-se e ganhou consistência pela participação ativa da pesquisadora nos cursos pesquisados, que permitiu maior colaboração e espontaneidade das pessoas para participarem. Elas foram questionadas, com o intuito de identificar o que estão aprendendo acerca da cultura e a língua do surdo, para incluí-lo na escola regular. As principais ações da escola regular são para oportunizar ao surdo a compreensão de pertencer, o que favorece a sua inclusão. A coleta de dados mostrou a importância da escola como facilitadora do processo científico e cultural que foram desprezados no passado, e agora podem ser relevantes quando são criadas condições de atender
\end{abstract}

* Doutoranda do Programa de Pós-Graduação em Educação, da Universidade Metodista de São Paulo - UMESP, sob orientação da Professora Doutora Norinês P. Bahia. Projeto de Pesquisa: Histórias de Vida: as trajetórias formativa e profissional de professores surdos da educação básica. 
aos surdos e suas necessidades na escola e na sociedade. O estudo das formas de comunicação dos surdos na sociedade contemporânea e o da comunicação dos professores com os alunos foram fundamentais para a compreensão desta pesquisa. Somente uma mudança na atuação do professor pode tornar suas aulas mais contextualizadas para o surdo.

Palavras-chave: Formação de Professores. Surdos. Escola Regular.

\title{
TEACHING TRAINING FOR WORK WITH DEAF STUDENTS IN REGULAR SCHOOLS
}

\begin{abstract}
The research focused on the courses of education and pedagogy, private HEIs, of São Paulo that, on the basis of act 10.436/2002 and on the decree 5.626/2005, obligatory that incluided the couse of Brazilian Sign Language - BSL. We optioned for qualitative analyses methodologically, that privilege the study on the phenomenon based on the insights of the own individual. The research drew a historical retrospective on the education of the deaf and it's way of interacting with other deaf and with listeners, facilitating the comparison between the proposal to integrate and the proposal to include within the school. The collected data was formed and gained consistency for the active researcher in the researched courses, which allowed greater collaboration and, spontaneity from people to participate. They were questioned with the aspiration to identify what they're learning about culture and deaf language in order to include this person in the regular school. The regurlar schools' main action to assist the deaf to the understanding of belonging, therefore, helps his inclusion. It showed the schools importance as a facilitator of the cientific and cultural process which were despised in the passed and now being able to be relevant when created conditions to assist the deaf and your needs in school and in Society. The study about means of comunicatio of the deaf in contemporary society and the comunication among teachers and students were fundamental for the comprehention of this research. Only a change in the
\end{abstract}


teacher's performance can transform into more contextulized classes for the deaf.

Key-words: Teacher Training. Deaf people. Regular School.

\section{INTRODUÇÃO}

O presente artigo objetiva discutir a relevância da inclusão da disciplina de Língua Brasileira de Sinais - Libras, nos currículos das Instituiões de Ensino Superior - IES, e ao refletirmos sobre esta realidade recente, acreditasmos que serao necessários vários enfrentamentos, principalmente no que se refere à Formação de Professores.

Pensamos em contemplar este tema em função do grande desafio que representa conhecer a comunicação e a escrita das crianças surdas, que estão sendo matriculadas atualmente em escolas regulares.

Deste modo, parece fundamental a investigação e a verificação dos cursos de Formação de Professores (Licenciatura) e Pedagogia, em IES particulares, da cidade de São Paulo que, a partir da Lei 10.436 (24 de abril de 2002), reconhece a Libras como meio legal de comunicação e expressão, com sistema linguístico e com gramática própria, e o Decreto 5.626 (22 de dezembro de 2005), que regulamenta a Lei 10.436 , que inclui a Libras como disciplina curricular obrigatória nos cursos de formação de professores para o exercício do magistério. Dessa forma, as instituições começam a ofertar em sua grade. Assim, surgiu a preocupação de pesquisar e mostrar como os alunos desses cursos de formação de professores estão sendo preparados para receber e trabalhar em sala regular com os alunos surdos.

No Brasil, Libras é a língua materna dos surdos, considerada língua 1 (L1), regulamentada por Lei, uma vez que esta se adquire espontaneamente e que eles podem dominá-la perfeitamente, pois utilizam o meio espaço-visual, que normalmente se desenvolve pelos indivíduos surdos, sendo a língua portuguesa a sua segunda língua, considerada L2, pois não é natural para os surdos, e sua apropriação fica comprometida. Para os ouvintes, o processo é proporcionalmente inverso. 
No entanto, para garantir que as pessoas surdas tenham acesso às escolas regulares, o uso da Libras, como meio de comunicação e instrução, precisa estar presente nas salas de aula, e o docente deve compreender a formação do pensamento do indivíduo surdo. Para isso, o professor precisa ser modificado para aceitar e valorizar a contribuição de cada um, conforme as suas condições pessoais. É indispensável um esforço conjunto da escola, da família e da sociedade para a aceitação e compreensão do diferente.

Deste modo, analisar os subsídios que as universidades estão oferecendo à formação desses profissionais para se inter-relacionarem e se comunicarem com os surdos e tornar possível a educação formal em sala regular é, quem sabe, o grande desafio em busca de esclarecimentos teóricos e práticos para entender como os surdos constroem as informações.

\section{A FORMAÇÃO DOCENTE PARA O TRABALHO COM ALUNOS SURDOS EM ESCOLAS REGULARES}

Os problemas auditivos não são raros e podem acontecer com pessoas de qualquer idade, raça ou classe social. Estima-se que quase $10 \%$ da população mundial possuem algum problema auditivo e que $1,5 \%$ da população brasileira é portadora de deficiência auditiva. A comunicação com os surdos, na maioria das vezes, é feita por meio de sinais.

Por muito tempo, os surdos ricos eram atendidos por professores, fonoaudiólogos e cuidadores para aprenderem a língua oral (orofacial), permanecendo a grande maioria à margem da escolaridade básica, assim os surdos e todos os deficientes sempre foram discriminados e marginalizados.

Os estudos a respeito da educação de surdos foram discutidos inicialmente na Suécia, Dinamarca, Finlândia há muito tempo antes que no Brasil. Foi somente no início da década de 90, que a educação de surdos tornou-se objeto de preocupação de muitos estudiosos brasileiros - (Brito, 1996; Quadros, 1997; Lacerda e Moura, 2000; Capovila, Lodi e Reily, 2004; Gil, 2005) entre outros. Selecionar uma metodologia adequada para educar os surdos requer de pais, educadores e especialistas, uma visão 
histórico-crítica da realidade surda ao longo dos tempos. De acordo com Lacerda (2000), podem-se distinguir duas iniciativas de educação de surdos, o oralismo e o gestualismo.

As pessoas que convivem com os surdos podem, em um movimento de troca de saberes, fornecer subsídios à pesquisadora para a identificação e avaliação, contribuindo com a ciência quando da sistematização de dados e de resultados, facilitando, portanto, o aprofundamento sobre a educação de surdos nas escolas regulares.

Após contato com vários autores como Quadros (2004), Lacerda (2000), Capovilla (2004), Moura (2000) e outros que abordam e analisam a língua de sinais, a inclusão de surdos na sociedade contemporânea permitiu pensar na investigação de como o deficiente auditivo e o surdo estão sendo recebidos pelas escolas.

Ao respeitarem o seu modo de se comunicar, ocorre uma dinâmica na relação do ser humano. Mesmo convivendo com situações as mais adversas possíveis, é necessário sempre dar condições para que todos tenham uma vida prazerosa e produtiva. Com essa visão, o todo é formado pelas partes, mas não é apenas a soma destas. A convivência com o surdo leva a escola a pensar em medidas necessárias para solucionar ou diminuir a exclusão, o preconceito, a discriminação e a intolerância. As principais ações da escola devem ser compreender e proporcionar ao surdo a oportunidade de pertencer, permitir a inclusão social dele na sala de aula.

Existem resistências da escola para que as crianças surdas sejam assistidas e não incluídas, considerando sua deficiência um empecilho para que elas tenham as condições favoráveis mínimas para o seu pleno desenvolvimento cognitivo, psíquico e emocional. As escolas que aprendem e se adaptam para aceitar a criança deficiente, em muitos casos, adequam-se apenas fisicamente, dando-lhes acessibilidade e não a dignidade e o respeito devidos a pessoas únicas e coletivas, como todas as pessoas de uma sociedade democrática devem ser consideradas. O surdo precisa muito mais que acessibilidade. 
Esse percurso mostrou a importância da escola como facilitadora dos processos científico e cultural, articulando-os e buscando compreender os vários fatores que foram desprezados no passado e agora podem ser relevantes quando são criadas condições de atender aos surdos e suas necessidades na escola e, indiretamente, na sociedade.

Conhecer a comunidade surda e compreender que os surdos são tão "normais" como os demais, e que têm necessidades educacionais especiais como todas as pessoas, cada uma ao seu modo, fez a pesquisadora pensar nos desafios diários que os professores iniciantes enfrentam e o que os motiva a pensar em um mecanismo de mudança, para que as pessoas surdas possam efetivamente frequentar e aprender em salas regulares.

Moura (2000) afirma que somos todos produtos da História, e que ela produz e se reproduz em cada um de nós. Isso nos leva a pensar que todo indivíduo, ao se descobrir, compreende sua realidade, ou seja, considera diferentes possibilidades de integração e transformação. Na prática, ao articular o saber, o conhecimento, a vivência e a comunidade, os deficientes compreendem a relação dele com o mundo que os cerca.

O estudo das formas de comunicação dos surdos na sociedade contemporânea e o da comunicação dos professores com os alunos são fundamentais para a compreensão dos sujeitos. É importante registrar que não se pode lutar pela implementação de algo que não se conhece e, ao discutir o problema, os envolvidos devem ter consciência do que estão fazendo.

O uso de sinais deve formar um tipo de representação significativa para os dois lados, ou seja, o emissor e o receptor precisam procurar diminuir os ruídos e compreender os codificadores e decodificadores para realmente se comunicarem (KOTLHER, 2000).

Temos que reconhecer que não pode haver processo de desenvolvimento se os indivíduos não estiverem incluídos numa ação constante de (re)construção do mundo. A inclusão não é fazer doações, é comprometimento pessoal e atitudinal de todos que participam do processo de inclusão para melhorar a condição de vida dos deficientes ou surdos. 
Os surdos, segundo Lacerda (2000), por muito tempo foram considerados incapazes de aprender, pois eram considerados retardados. Há pouco tempo foi admitido que eles são capazes de pensar e aprender e, com isso, os objetivos da educação de surdos passaram a incluir procedimentos pedagógicos que facilitam a comunicação com o ouvinte.

Há algumas décadas o atendimento educacional de pessoas com necessidades educacionais especiais está assegurado na Constituição Brasileira, na medida em que a educação é considerada direito de todos.

[...] a educação é direito e dever do Estado e da Família [...] o dever do Estado coma educação será efetivado mediante a garantia de [...] atendimento educacional especializado aos portadores de deficiência, preferencialmente na rede regular de ensino (ARTIGOS 205 e 208, 1988).

A língua de sinais, por sua vez, foi impulsionada na década de 90, com a Lei de Diretrizes e Bases da Educação Nacional - LDBEN, pela ideologia de uma escola para todos. Para que a inclusão bem-sucedida desses educandos ocorra, é necessária a inserção de todos, sem distinção de condições linguísticas, sensoriais, cognitivas, físicas, emocionais, étnicas, socioeconômicas ou outras e requer uma proposta que represente valores simbólicos importantes, condizentes com a igualdade de direitos e de oportunidades educacionais para todos (PCN, 2002).

Este trabalho justificou-se em função do grande desafio que a Lei 10.436, de 2002, dispôs sobre a Língua Brasileira de Sinais - Libras, que reconheceu essa língua como meio legal de comunicação e expressão de ideias e fatos oriundos da comunidade surda brasileira. Regulamentada pelo Decreto 5.626, de 2005, que insere Libras como disciplina curricular obrigatória nos cursos de formação de professores para o exercício do magistério, fonoaudiologia e como disciplina optativa para os demais cursos de graduação e na educação profissional. No entanto, a quantidade hora/aula para essa disciplina não foi predeterminada 
nem a modalidade (presencial ou a distância), o que deixa as IES livres para as várias combinações.

A pesquisa ocorreu em situações diversas, com oportunidade de exercer efetivamente a prática e a troca de saberes acadêmicos com os saberes empíricos, proporcionando a compreensão da realidade e da necessidade social e cultural do surdo.

A relevância social deste trabalho sustentou-se quando os elementos foram analisados e contribuíram para melhor entendimento, pelos educadores, quando perceberam os possíveis caminhos para o enfrentamento das dificuldades e possibilidades de inclusão dos surdos no mundo que os cerca.

Percebemos que as pessoas estão mais acessíveis ao diferente, sendo o uso de Libras, como alternativa de comunicação com as pessoas surdas, fundamental, mas nem sempre praticada por desconhecê-la.

Como a língua e as várias linguagens estão presentes no nosso dia a dia, conhecê-las não é só uma exigência da escola, mas uma necessidade social e de cada indivíduo.

A linguagem é instrumento de comunicação entre as pessoas em sociedade; é conceituada, também, como um mecanismo usado para a expressão do mundo e do pensamento e, ainda, como uma forma ou processo de interação social.

Objetivando descrever sobre a preparação oferecida aos futuros professores para receberem alunos surdos em suas salas de aula em escolas regulares, esta pesquisa mostrou-se como um instrumento de conhecimento e reconhecimento de seus pares, que buscou identificar a relevância em conhecer a comunicação sinalizada e escrita dos surdos.

Somente uma mudança na atuação do professor em sala de aula, incentivando a prática da inclusão do surdo, pode tornar suas aulas mais contextualizadas e respeitadas por seus alunos, que compreenderão a comunicação praticada.

$\mathrm{Na}$ busca de discutir com os futuros docentes como eles estavam se preparando para receber em suas salas de aula, nas escolas regulares, alunos surdos e ouvintes juntos, foi questionado o tempo de contato com a Libras, e a resposta foi que a carga horária era de quarenta aulas/ano. E outras quarenta aulas 
para estudarem todas as outras deficiências e síndromes que normalmente aparecem nas escolas.

Questionados acerca do tempo, eles reconhecem que é pouco, e muitos afirmam não se esforçarem, porque acham que quanto mais contato com deficientes tiverem, tanto mais surdos e deficientes aparecerão em suas salas, que hoje já são numerosos.

Os docentes mais articulados com a sociedade, que realmente abraçaram a profissão como opção de realização pessoal, dizem que os cursos gratuitos, para os que estão em escolas particulares, são caros. O Estado e o município de São Paulo investem em cursos de Libras para os profissionais da rede.

Em termos metodológicos, optamos pela investigação qualitativa, que privilegia o estudo do fenômeno com base nas percepções dos próprios sujeitos. A abordagem qualitativa possibilitou conhecer o objeto investigado, fornecendo elementos esclarecedores.

De acordo com a obra de Lüdke e André (1996), que serviu de orientação para a parte técnica deste trabalho, pretendeu-se confrontar as atitudes que a sociedade tem perante o deficiente auditivo.

A abordagem qualitativa preocupa-se muito mais com o processo, com sua validade e com sua relevância, do que com o produto (BIKLEN \& BOGDAN, 1994).

Optamos pela pesquisa qualitativa, porque esta permite abordar o ambiente natural dos professores e futuros professores como fonte direta dos dados. Segundo Lüdke e André (1986, p. 12) "o significado que as pessoas dão às coisas e à sua vida são focos de atenção especial pelo pesquisador", o que permite a compreensão dos elementos que norteiam as relações ensino-aprendizagem.

A pesquisa envolveu uma retrospectiva histórica da educação dos surdos e sua forma de interagir com outros surdos e com ouvintes. Nesse percurso, procuramos identificar aspectos educacionais percorridos para a construção desse elo.

O oralismo e o gestualismo sempre foram as bases familiares para a compreensão dos seus sujeitos. Sendo o universo da pesquisa constituído por futuros professores, que trabalharão 
com surdos para compreender e verificar o modo vivente e comunicacional dos pares, buscamos uma pesquisa qualitativa.

Essa abordagem facilitou a comparação entre a proposta de integração e a proposta da inclusão no âmbito da escola, sabendo-se que a inserção das pessoas no percurso da vida acontece via sistema cascatas, uma conquista após a outra.

Preparando, discutindo e compreendendo a criança surda, os professores poderão refletir e identificar a evolução conceitual e política da oportunidade em que se analisa uma "situação concreta": os surdos na escola regular.

Ao valorizar a vida do outro, percebemos a atitude de não discriminação e aceitação do diferente, sem que ninguém deva sentir-se bonzinho por ter agido assim.

A coleta de dados formou-se e ganhou consistência pela participação ativa da pesquisadora nos cursos de Formação de Professores (Licenciatura) e Pedagogia, que permitiu maior colaboração e espontaneidade dos alunos para participarem da pesquisa.

A pesquisadora entrevistou alunos e alunas dos cursos de Formação de Professores e Pedagogia, com o intuito de identificar o que estão aprendendo para a compreensão e inclusão do surdo em sala de aula regular. A proposta era percebermos o que as IES estão efetivamente colocando em sua grade curricular, como conteúdo, carga horária e trabalhos extracurriculares que contribuam com a formação dos futuros professores.

Ao final desses levantamentos junto aos futuros professores, observamos que nas licenciaturas - formação de professores - a carga horária é de quarenta horas de aulas sobre língua brasileira de sinais. O que diferencia as licenciaturas da Pedagogia é que na última há disciplina de inclusão, ou diversidades para discutir sobre as outras modalidades de deficiência e inclusão, ou seja, às vezes parece ter uma carga horária maior, mas se a disciplina precisa dar conta de todas as deficiências, em nada muda.

Podemos acrescentar que a pesquisa evidenciou um esforço de inclusão social e cultural por parte dos docentes, na tentativa de melhor compreender a comunidade surda, sua trajetória e suas necessidades. Longe ainda do ideal, mas conscientes de 
que são responsáveis pela qualidade de ensino que oferecem, os educandos têm a responsabilidade de integrar, incluir e ensinar todo tipo de deficiente em sala de aula.

\section{REFERÊNCIAS}

BRASIL. Constituição (1988). Constituição da República Federativa do Brasil. Promulgada em 5 de outubro de 1988 e alterada por Emendas Constitucionais, até a de $\mathrm{n}^{\circ}$ 42, de 19 de dezembro de 2003.

BRASIL. Lei 10.436. Dispõe sobre a Língua Brasileira de Sinais - Libras, 24 de abril de 2002.

BRASIL. Ministério da Educação e Cultura. Lei nº 9.394, de 20 de dezembro de 1996. Estabelece as Diretrizes e Bases da Educação Nacional. Diário Oficial da União. Seção 1.

BRASIL. Secretaria de Educação Fundamental. Parâmetros Curriculares Nacionais. Brasília: MEC/SEF, 2000.

CAPOVILLA, Fernando César; RAPHAEL, Walkiria Durar. Enciclopédia da Língua de Sinais Brasileira: o mundo do surdo em libras, vols. 1 e 2 - Educação, São Paulo: Fundação Vitae Fapesp e USP, Imprensa Oficial do Estado de São Paulo, 2004.

KOTLER, Philip. Administração de marketing, 2. ed. São Paulo: Prentice Hall, 2000.

LACERDA, C. B. F. Os processos dialógicos entre alunos surdos e educador ouvinte: examinando a construção de conhecimentos. UNICAMP. Tese de Doutoramento, 1996.

LACERDA, C. B. F. de; NAKAMURA, H.; LIMA, M. C. P. (orgs.). Fonoaudiologia: surdez e abordagem bilíngüe. São Paulo: Ed. Plexus, 2000.

LODI, A. C. B. A leitura como espaço discursivo de construção de sentidos: oficinas com surdos. Tese de Doutorado. Pontifícia Universidade Católica de São Paulo, 2004.

LÜCKE Menga e ANDRE, Marli E. D. A. Pesquisa em educação: abordagens qualitativas. São Paulo: EPU, 1996.

MOURA, M. C. O Surdo: caminho para uma nova identidade. Rio de Janeiro: Revinter, 2000.

QUADROS, Ronice Muller de. Educação de surdos: aquisição de linguagem. Porto Alegre: Artmed, 1997.

QUADROS, Ronice Muller de; KARNOPP, Lodenir Becker. Língua de sinais brasileira: estudos linguísticos. Porto Alegre: Artmed, 2004. 